\title{
The response of chironomid assemblages to mineral richness gradient in the Western Carpathian helocrenes
}

\author{
Vit Syrovátka', Jindriška Bojková' and Vanda Rádková'
}

\begin{abstract}
Syrovátka V, Bojková J and Rádková V. 2012. The response of chironomid assemblages to mineral richness gradient in the Western Carpathian helocrenes. Fauna norvegica 31: 117-124.
\end{abstract}

Chironomid assemblages of helocrene springs were investigated in the Western Carpathians in order to identify potential effect of water mineral richness on the taxonomic structure of the assemblages. A complex gradient considering water chemistry and substratum was used as a measure of basicity (mineral richness). Taxonomic structure, total abundance and abundance of most frequent taxa were related to this gradient with regards to two contrasting habitats: trickle (A) and water-loged soil with standing water (B). The variance in chironomid assemblage attributable to basicity was estimated and tested via PERMANOVA as well as the possible effect of the other environmental variables. The response of individual taxa was examined using GAM. The results indicate a strong relationship between basicity and substratum characteristics, with coarser mineral substrata at basic and high amount of organic matter at acidic conditions. Although water chemistry was correlated with and inseparable from these substratum properties, it could not be substituted with them, as they discriminated well only between acidic and basic springs, but did not follow the basicity gradient in either acidic or basic group of springs. Chironomid assemblage showed a strong and systematic response to the complex gradient of mineral richness, which explained the largest portion of variance in both the habitat $\mathrm{A}$ and $\mathrm{B}$ faunal data and was projected on the first axes of both NMDS ordinations. The assemblage response could be documented by the preference of several taxa for particular mineral richness conditions, while the number of taxa seemed to be highest in the middle of the basicity gradient. As only 17 samples were analysed so far, the results are considered preliminary and, hopefully, more confident results will be available in near future.

doi: 10.5324/fn.v31i0.1403. Received: 2011-11-01. Accepted: 2012-05-30.

Published on paper and online: 2012-10-17.

Keywords: Chironomidae, spring fens, basicity, water chemistry, mineral richness

1. Department of Botany and Zoology, Faculty of Science, Masaryk University, Kotlárská 2, CZ61137 Brno, Czech Republic

Corresponding author: Vit Syrovátka

E-mail: syrovat@sci.muni.cz

\section{INTRODUCTION}

Springs are unique transitional biotopes where stygobiontic, aquatic and terrestrial fauna come together. Springs in temperate regions are highly valuable in terms of biodiversity as they harbour cold stenothermic species otherwise inhabiting alpine and arctic areas. They are rather limited in size, which makes them very vulnerable to anthropogenic impacts (Orendt 2000, Lencioni et al. 2011) and leads to a relatively low number of species found in individual springs (Lindegaard et al. 1998).
Extensive studies on springs are needed to gather information about their functioning for the effective management of spring ecosystems.

Much effort in the last decade was exerted to establish a classification of springs and to identify environmental variables that determine the composition of spring faunal communities. Researchers have agreed on the major distinction between limno-, rheo-, and helocrene springs, as they were distinguished by Thienemann (1924) (Blackwood et al. 1995; Ferrington 
1998; Hahn 2000; Von Fumetti \& Nagel 2011). However, in the identification of other environmental variables shaping spring faunal assemblages, opinions of researchers vary. Water discharge associated with spring stability (Erman \& Erman 1995; Smith \& Wood 2002; Wood et al. 2005; Von Fumetti et al. 2006; Von Fumetti \& Nagel 2011), substratum properties (Hahn 2000; Ilmonen \& Paasivirta 2005) or temperature associated with altitude (Ferrington 1998; Lencioni et al. 2011) or latitude (Ilmonen et al. 2009) have been identified as the most important in most studies. Of course, it is a matter of available environmental gradients and spatial scale and there are few studies acknowledging water chemistry might have a significant influence on spring assemblages (Erman \& Erman 1995; Lencioni et al. 2011). However, in these studies water chemistry (particularly $\mathrm{pH}$ and associated mineral richness) was closely correlated with some other variables, the effects of which were inseparable. Only Hahn (2000) observed different macroinvertebrate assemblages at acidic rheocrenes compared to non-acidic, and Glazier \& Gooch (1987) observed insectdominated assemblage in low $\mathrm{pH}$ springs, while amphipoddominated assemblage occurred in medium to hardwater springs.

Searching for important variables, other than those distinguishing between the three main spring types, may be obscured when assemblages of all the three types are analyzed together and studies conducted at a single spring-type might prove fruitful. Among the three major spring types, helocrenes offer a high variety of habitats (Lindegaard 1995), are inhabited mainly by dipterans including Chironomidae (Hahn 2000) and are the most common in the Western Carpathians. They are strongly influenced by chemistry of groundwater they are supplied with, as the variance in bedrock induces the existence of a basicity (mineral richness) gradient (Hájek et al. 2006). This gradient, well reflected by the sum of $\mathrm{Ca}^{2+}$ and $\mathrm{Mg}^{2+}$ ions, determines the taxonomic composition and richness of various organism groups (e.g. algae Poulíčková et al. (2003), bryophytes and vascular plants (Hájek et al. 2006), Testacea (Opravilová \& Hájek 2006), or Mollusca (Horsák \& Hájek 2003). However, to the best of our knowledge there are no studies dealing with the direct effect of the basicity gradient on spring benthic macroinvertebrate or insect assemblages.

Therefore, within this study we analyze data from 17 helocrene spring sites, distributed along the mineral richness gradient in the Western Carpathians to determine the effect of basicity on helocrene chironomid assemblages. Within each site two contrasting habitats were sampled: trickle (flowing water) and waterlogged soil with standing water. The data from these habitats are analyzed separately to stress the difference in the assemblage response.

\section{MATERIAL AND METHODS}

\section{Study area and sites}

The studied spring fens (helocrenes) were located on the western margin of the Western Carpathians (borderland between the Czech Republic and Slovakia, altitude between 450 and $750 \mathrm{~m}$ a.s.l.), which is a part of the Western Carpathian flysch belt. Within the study area the groundwater chemistry varies from extremely rich calcareous water, which supports the cold water travertine (tufa) formation, through waters rich in calcium, sodium and potassium without tufa-formation, to acidic waters rich in iron, silica and sulphates but poor in all the other elements (Hájek et al. 2002). The 17 studied helocrenes were distributed along the whole range of mineral-richness gradient from extremely rich fens to acidic, mineral poor fens within the Western Carpathians.

\section{Field sampling}

Chironomid larvae were sampled at the 17 sites three times - in May, July, and September 2006 - in order to capture the majority of chironomid species occurring at the sites. During each sampling campaign two contrasting habitats were sampled at each site; the flowing part of the spring fen (habitat A) and the waterlogged soil with standing water (habitat B). The sampled areas were well supplied with ground water and did not dry out during the season.

Single samples were taken from a plot of $25 \times 25 \mathrm{~cm}$, from where the vegetation and the upper bottom layer were collected into the depth of approximately five centimeters. Samples were elutriated through a net (500 $\mu \mathrm{m}$ mesh size) and the substratum was kept in $4 \%$ formaldehyde solution. All chironomid larvae were hand-picked in a laboratory under a stereomicroscope and identified.

To describe the environmental conditions at the sampling plots, water conductivity, temperature, dissolved oxygen, and $\mathrm{pH}$ were measured in situ by portable instruments (WTW Multi 340i/SET) before each sampling. Moreover, at each sampling occasion a $100 \mathrm{ml}$ sample of substratum was taken just next to the sampling plot to examine total organic carbon (TOC, Shimadzu TOC- $\mathrm{V}_{\mathrm{CPH}}$ ). Median values of the seasonally measured variables were used to characterize the overall environmental conditions at sites.

Substratum samples of the upper five $\mathrm{cm}$ bottom layer were taken in August 2006 from a plot of $25 \times 25 \mathrm{~cm}$ adjacent to each sampling plot for substratum analysis. The weight of mineral substratum, fine particulate organic matter (FPOM; fraction < $1 \mathrm{~mm}$ ) and coarse particulate organic matter (CPOM; fraction $>1 \mathrm{~mm}$ ) were determined. CPOM was further sorted according to the origin (Sphagnum spp., brown mosses, vascular plants, and wood/leaves) and all fractions were weighed and expressed as the proportions of the total weight of CPOM. The share of particulate organic matter (POM share) was calculated as the proportion of the sum of the CPOM and FPOM weights in the total substratum weight. Upper quartile, median, and lower 


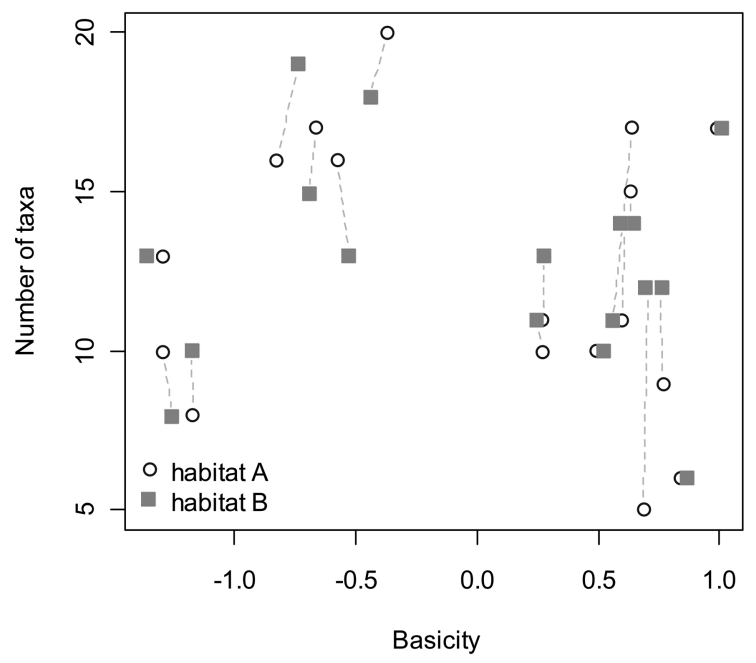

Figure I. The relationship between the number of chironomid taxa at sites and the basicity gradient. Samples from the same sites are connected by dash-lines. quartile diameter of mineral substratum particle size $\left(\mathrm{Q}_{75}\right.$, $\mathrm{Q}_{50}, \mathrm{Q}_{25}$ ) were determined and used for the description of the substratum particle size.

Water samples were collected in autumn 2006 using a shallow dish, when water chemistry is relatively stable (Hájek and Hekera 2004), and the content of soluble $\mathrm{Na}^{+}, \mathrm{K}^{+}, \mathrm{Ca}^{2+}$, $\mathrm{Mg}^{2+}, \mathrm{Al}, \mathrm{Fe}, \mathrm{Mn}, \mathrm{Pb}^{2+}, \mathrm{Cl}^{-}, \mathrm{SO}_{4}^{2-}, \mathrm{NO}_{3}^{-}$and $\mathrm{PO}_{4}^{3-}$ ions were measured in an accredited laboratory.

\section{Data analysis}

Seasonal counts of taxa within each site-habitat combination were pooled giving a number of 17 samples for each of the two habitats (i.e. 34 samples in total).

Median values of seasonally measured environmental variables were calculated, ensuring the data entering subsequent analyses characterized the overall nature of the habitats throughout the seasons. Environmental data were further examined using dotcharts and transformed when necessary: water discharge and chemical variables were square root transformed so that their distribution was close to normal.

Table I. Total abundance and frequency of taxa within habitat A and B samples. The taxa preference for acidic (acid.), moderate (mod.) or basic (bas.) conditions is indicated. Only taxa occurring in at least 4 samples of either habitat A or habitat B data sets are listed.

\begin{tabular}{|c|c|c|c|c|c|c|c|}
\hline \multirow[b]{2}{*}{ Taxon } & \multirow[b]{2}{*}{ Shortcode } & \multicolumn{3}{|c|}{ Habitat A } & \multicolumn{3}{|c|}{ Habitat B } \\
\hline & & Abund. & Freq. & Pref. & Abund. & Freq. & Pref \\
\hline \multicolumn{8}{|l|}{ Tanypodinae - Macropelopiini } \\
\hline Macropelopia sp. & MacrSp & 360 & 11 & acid. & 252 & 14 & acid. \\
\hline \multicolumn{8}{|l|}{ Tanypodinae - Natarsiini } \\
\hline Natarsia sp. & NataSp & 17 & 8 & mod. & 47 & 8 & - \\
\hline \multicolumn{8}{|l|}{ Tanypodinae - Pentanuerini } \\
\hline Krenopelopia sp. & KrenSp & 70 & 9 & - & 87 & 14 & acid. \\
\hline Trissopelopia sp. & TrisSp & 39 & 7 & - & 8 & 3 & - \\
\hline \multicolumn{8}{|l|}{ Orthocladiinae } \\
\hline Brillia modesta (KIEFFER, 1909) & BriMod & 32 & 10 & - & 8 & 3 & - \\
\hline Chaetocladius piger-Gr. & ChaePigGr & 190 & 8 & - & 50 & 9 & - \\
\hline Heleniella ornaticollis (EDWARDS, 1929) & HelOrn & 81 & 10 & - & 44 & 9 & bas. \\
\hline Heterotrissocladius marcidus (WALKER, 1856) & HetMar & 93 & 5 & - & 140 & 5 & acid. \\
\hline Limnophyes sp. & LimSpJuv & 18 & 7 & - & 19 & 7 & acid. \\
\hline Parachaetocladius abnobaeus (WÜLKER, 1959) & ParAbn & 159 & 9 & mod. & 60 & 13 & - \\
\hline Parametriocnemus stylatus (KIEFFER, 1924) & ParSty & 102 & 13 & bas. & 90 & 11 & bas. \\
\hline Paraphaenocladius pseudirritus STRENZKE, 1950 & ParPse & 28 & 2 & - & 24 & 7 & - \\
\hline Rheocricotopus effusus (WALKER, 1856) & RheEff & 12 & 8 & - & 30 & 11 & - \\
\hline Synorthocladius semivirens (KIEFFER, 1909) & SynSem & 46 & 5 & bas. & 3 & 3 & - \\
\hline Tvetenia bavarica/calvescens & TveBaCa & 36 & 5 & bas. & 12 & 4 & - \\
\hline \multicolumn{8}{|l|}{ Chironominae - Chironomini } \\
\hline Paratendipes nudisquama (EDWARDS, 1929) & ParNud & 189 & 10 & acid. & 276 & 12 & acid. \\
\hline Phaenopsectra sp. & PhaeSp & 25 & 4 & mod. & 51 & 6 & - \\
\hline Polypedilum scalaenum-Gr. & PolScaGr & 197 & 11 & mod. & 65 & 11 & - \\
\hline \multicolumn{8}{|l|}{ Chironominae - Tanytarsini } \\
\hline Micropsectra spp. & $\mathrm{MicSp}$ & 121 & 7 & - & 324 & 11 & bas. \\
\hline Neostempellina thienemanni REISS, 1984 & NeoThi & 57 & 4 & bas. & 3 & 1 & - \\
\hline Stempellina bausei (KIEFFER, 1911) & SteBauGr & 23 & 3 & - & 82 & 4 & mod. \\
\hline Stempellinella ciliaris/flavidula & SteCilFla & 59 & 7 & mod. & 69 & 6 & bas. \\
\hline
\end{tabular}



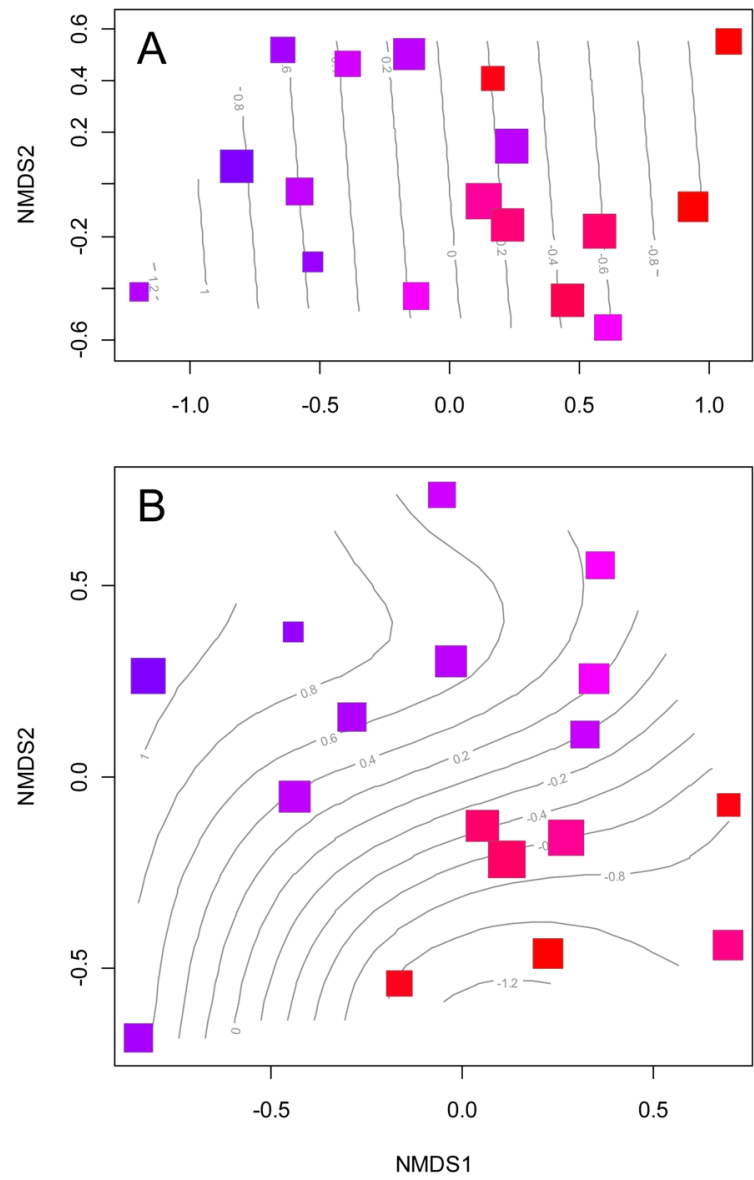

Figure 2. NMDS ordination diagram of habitat A (A) and B (B) samples. The symbol sizes are proportional to the number of taxa found in the samples, while the color indicates the basicity conditions at the sites (red - most acidic, blue - most basic). The gradient of basicity is fitted into the ordination diagrams using thinplate splines and is indicated by the grey contour lines. The fit statistics were: R-sq.(adj) $=0.601, \mathrm{p}=0.0006$ and R-sq.(adj) $=0.826, \mathrm{p}=0.0015$ for habitat $\mathrm{A}$ and $\mathrm{B}$ respectively.

Principal Component Analysis (PCA) was performed on the environmental data in order to identify main gradients in the data and to assess the relationships among the variables. Most of the variables were related to each other, reflecting a complex gradient of mineral richness (basicity). As the gradient of basicity (mineral richness) was of primary interest, we decided not to choose one of the raw variables for its representation, but to compute a more complex gradient from the variables most reflecting mineral richness instead. For this, we used those variables that strongly correlated (Spearman's rho $>0.7$ ) with the sum of $\mathrm{Ca}^{2+}$ and $\mathrm{Mg}^{2+}$ ions. These variables were the same for both habitats: $\mathrm{Ca}^{2+}, \mathrm{Mg}^{2+}$, conductivity, $\mathrm{pH}, \mathrm{SO}^{4-}$, TOC, POM share, and Sphagnum spp. The first component of PCA performed on these variables was used as a complex variable representing the mineral richness (basicity) gradient.
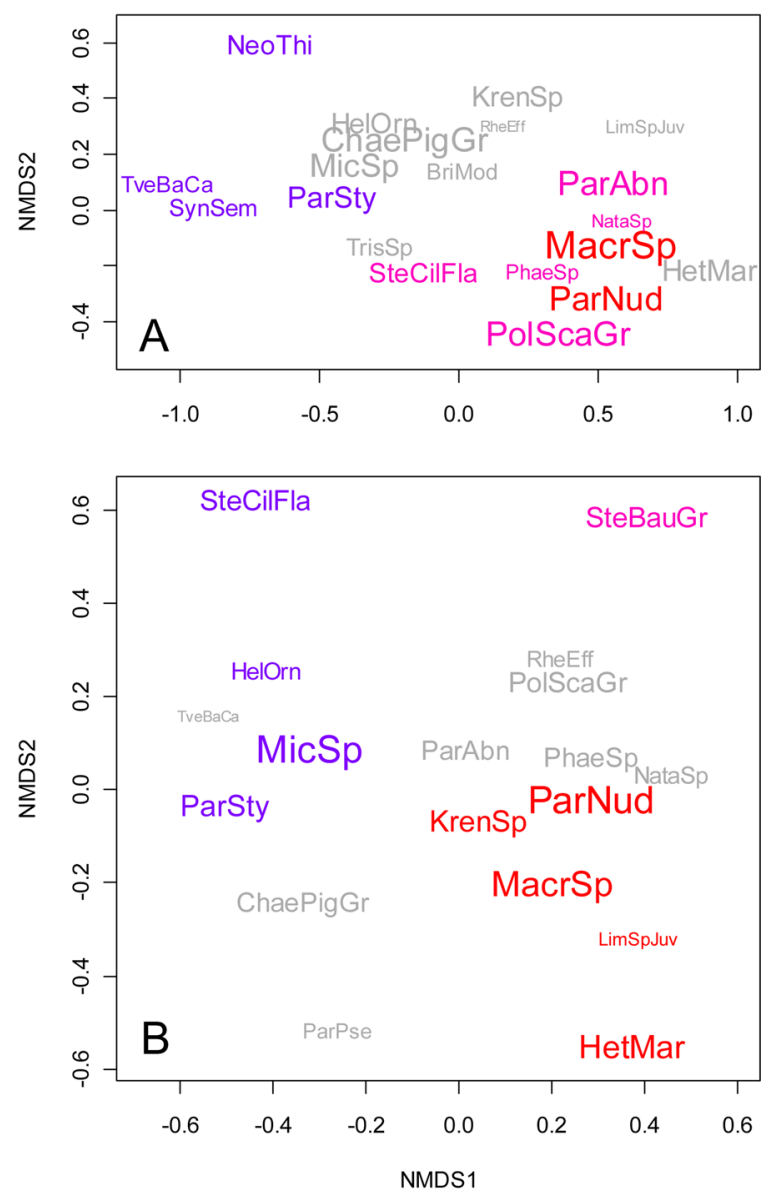

Figur 3. NMDS ordination diagram of habitat A (A) and B (B) taxa. The font size is proportional to the taxon abundance while the color indicates its preference for acidic (red), moderate (violet) and basic (blue) conditions. Taxa in grey did not show any preference. Only taxa occurring in at least four sites are shown. For taxa abbreviations see Table 1.

Since most environmental variables were related to each other, variable selection was needed: first, highly correlating variables (correlation $>0.8$ ) and in the next step variables with the highest Variance Inflation Factors (VIF) were removed step by step until all of them had VIF $<10$. The whole variable selection procedure was run for each habitat separately, leading to slightly different sets of variables for the two habitats. Thirteen variables (temperature, water discharge, $\mathrm{NH}_{4}{ }^{+}, \mathrm{PO}_{4}{ }_{4}^{3-}$, $\mathrm{Cl}^{-}, \mathrm{Al}, \mathrm{Fe}, \mathrm{K}^{+}$, the amount of CPOM and FPOM, the share of plants and moss within the organic matter and basicity) were common to both habitats but, additionally, $\mathrm{Q}_{50}$ (median particle size) was included in the data-set of the habitat A.

Permutational Multivariate Analysis of Variance Using Distance Matrices (PERMANOVA, Anderson 2001) was employed to determine the amount of variation in the species data attributable to the environmental variables. A forward stepwise approach was applied: variables were added step by 
step into the model and each turn the variable with the highest portion of variance explained was kept, until no other variable significantly increased the portion of the variance explained (p $<0.05$ ). The significance of the variables was tested by 9999 permutations. The species data were $\log (x+1)$ transformed and Bray-Curtis dissimilarity was used as the distance measure.

To illustrate the shift in the assemblage taxonomic structure along the gradient of mineral richness, the abundance of the taxa occurring in at least 4 samples was modeled as a function of the basicity gradient using Generalized Additive Models (GAM, Wood 2006) with the poisson family corrected for overdispersion (i.e. quasipoisson) for each habitat separately. Since the total number of samples was rather low (17), the models were used as an indication of the species' response to basicity, with the motivation to identify those species that were likely to show a preference for either acidic, moderate or basic conditions. For this reason, all the models with the $p$ value of the smoother lower than 0.1 were considered and the respective taxa were classified according to the position of their predicted optimum on the mineral richness gradient (lower, middle, and upper third) into three classes: preferring acidic, moderate, or basic conditions.

All taxa occurring in at least 4 samples were displayed in the Non-metric Multidimensional Scaling (NMDS, Cox \& Cox 2001) diagram in relation to the gradient of mineral richness fitted into the diagram using thinplate splines ('ordisurf', vegan package). An attempt was made to fit into the diagram also the other variables identified by PERMANOVA as important to chironomid assemblage in order to identify main gradients in the NMDS ordination.

All analyses were performed in R (R Development Core Team 2011) with the use of 'vegan' (Oksanen et al. 2011) and 'mgcv' (Wood 2006) packages.

\section{RESULTS}

\section{Faunal data}

In total, 4202 chironomid larvae belonging to 60 taxa of four subfamilies were identified. Chironominae were the most abundant subfamily (1665 individuals in 12 taxa) followed by Orthocladiinae, which were the most taxa-rich (1619 individuals in 40 taxa). The abundance and number of taxa in Tanypodinae and Prodiamesinae were much lower (911 and 7 individuals in 7 and 1 taxa, respectively). The total abundance and number of taxa were slightly higher at habitat B (2135 individuals in 52 taxa) compared to habitat A (2067 individuals in 48 taxa). The number of taxa in samples ranged between 5 and 20 at habitat $\mathrm{A}($ median $=11)$ and between 6 and 19 at habitat $\mathrm{B}($ median = 13).

\section{Gradient of basicity}

The gradient of basicity reflected best $\mathrm{pH}$ (Spearman's rho = 0.93 and 0.94 at habitat $\mathrm{A}$ and B), conductivity (rho $>0.90$ ) and the amount of ions of several elements $\left(\mathrm{Ca}^{2+}, \mathrm{Mg}^{2+}, \mathrm{SO}_{4}^{2-}\right.$ rho $>0.8)$. However, dissolved oxygen $(\mathrm{DO}$, rho $=0.64$ and 0.65$)$ and the amount and grain size of mineral substratum (ANORG, $\mathrm{Q} 50$, rho $=0.64$ and 0.60 at habitat $\mathrm{A}$ and 0.52 and 0.30 at habitat B) increased, while the amount of organic matter (TOC, rho $=-0.80$ and -0.81$)$ and the share of particulate organic matter (POM share, rho $=-0.76$ and -0.54 ) and Sphagnum spp. (rho $=-0.83$ at both habitats) decreased along the gradient of basicity. The correlations with the mineral substratum variables were weaker, especially at the habitat B, nevertheless, mineral richness gradient should be regarded as a complex gradient considering both the chemical and substratum features.

\section{Total abundance and number of taxa}

Both the total abundance and the number of taxa were highest in the middle of the basicity gradient and lower at the margins (Figure 1). However, the variance of both the abundance and number of taxa was higher at the basic end of the gradient. The number of taxa was closely related to the log total abundance (Spearman's rho $=0.84$ and 0.62 at habitat $\mathrm{A}$ and B) and, similarly, both the total abundance and number of taxa at habitat A were correlated with that of habitat B (rho $=0.71$ and 0.73 for total abundance and number of taxa). Therefore, only the response of the number of taxa to the gradient of basicity is shown.

\section{Assemblage structure vs. environment}

Basicity explained the largest portion of variance in the species data in both data-sets during the forward selection process of PERMANOVA. Nevertheless, the portion of variance it explained was lower within the habitat B dataset $(14.4 \%$ of variance explained, $\mathrm{p}=0.0009)$ compared to habitat $\mathrm{A}(20.4 \%$, $\mathrm{p}=0.0001)$. Substratum grain size $(\mathrm{Q} 50)$ and water temperature (T) contributed to the portion of variance explained at the habitat A by $9.6 \%$ and $9.2 \%$, though their significance was close to the $5 \%$ significance level ( 0.018 and 0.031 , respectively). At habitat $\mathrm{B}$ only the amount of $\mathrm{Al}$ contributed with $9.6 \%$ of variance and with $\mathrm{p}$ value close to the $5 \%$ significance level as well ( $\mathrm{p}$ $=0.035$ ).

In summary, $39.3 \%$ of variance in the chironomid data could be attributed to basicity, substratum grain size and temperature at the habitat $\mathrm{A}$, while $24.1 \%$ to basicity and the amount of $\mathrm{Al}$ at the habitat $\mathrm{B}$.

Fitting the variables that were significant in PERMANOVA into the faunal NMDS ordinations confirmed the importance of mineral richness to the chironomid assemblage taxonomic structure. It was fitted best of all the available variables and followed the first axis of both (habitat A and B) ordinations (Figure 2). Besides basicity, also Q50 could be significantly fitted into the habitat A ordination, but followed a pattern similar to basicity (not shown). Neither water temperature at habitat $\mathrm{A}$, nor $\mathrm{Al}$ at habitat $\mathrm{B}$ could be fitted into the respective NMDS diagrams, suggesting they were not of the primary influence on the assemblage taxonomic structure. 
The stress values of the NMDS ordinations were 0.14 and 0.20 for habitat $A$ and $B$ respectively suggesting the taxonomic structure of the assemblages of habitat $\mathrm{B}$ was more complex or non-systematic with lower portion of variance explained by the two ordination axes.

\section{Individual taxa vs. gradient of basicity}

Considering habitat A and B separately, 20 and 18 taxa occurred in at least four samples respectively, and their responses to the gradient of basicity were tested.

Out of these, 16 taxa were common to both habitats giving a total of 22 taxa tested. With regard to habitat A, two taxa showed an indication of preference (i.e. their response to the gradient of basicity was significant at the 0.1 level) for acidic conditions, 5 for moderate and 4 for basic conditions, while 5 for acidic, one for moderate and 4 for basic conditions at habitat B (Table 1). These taxa are displayed in the NMDS diagram and their preferences are indicated by different formatting (Figure 3).

\section{DISCUSSION}

\section{Faunal data}

The taxonomic composition of the chironomid assemblages was generally in agreement with previous studies at springs (e.g. Blackwood et al. 1995, Ferrington et al. 1995; Linegaard 1995; Lencioni et al. 2011). Orthocladiinae have been reported to be the most abundant and species rich subfamily in most springs and this holds partially also for this study. We observed slightly higher total abundance of Chironominae compared to Orthocladiinae, which was mainly caused by high abundances of Paratendipes nudisquama at acidic sites (both the habitat A and B) and Micropsectra spp. mainly at habitat B. However, the number of Orthocladiinae taxa was higher than of any other subfamily with two thirds of all the taxa represented by Orthocladiinae.

We did not observe any Diamesinae, which might have been caused by relatively low altitude of the studied springs, but more probably by overlooking them due to their early emergence (Coffman 1973).

\section{Gradient of basicity}

Water chemistry associated with the gradient of basicity (mineral richness) affects the spring fauna in several ways. First, the availability of ions and nutrients together with $\mathrm{pH}$ determines the vegetation, forming and surrounding the spring habitats (Hájek et al. 2006). Further, at low pH microbial activity is reduced leading to slow decomposition and accumulation of organic matter, thus, changing the substratum properties. On the opposite end of the basicity gradient, high concentration of minerals (esp. $\mathrm{Ca}^{2+}$ ions) cause tufa (precipitated calcium carbonate) formation (again, changing the nature of substratum), which may precipitate on the surface of organisms and affect them directly.

The basicity gradient, therefore, represents a complex environmental shift from acidic, organically rich springs, to basic springs affected by tufa formation. A correlation between the basicity gradient and substratum properties (e.g. the share of POM or Sphagnum spp., the share and size of mineral particles) was also observed in our study. However, some of these correlations reflected just the difference between acidic and basic springs and when analysed (or just plotted) separately within each acidic and basic springs, no patterns between the basicity gradient and those variables were observed (Q50, ANORG, Sphagnum spp. within basic springs). That is also why Q50 contributed significantly to the explained variance within the habitat A dataset, despite that the gradient of basicity had been already included in the model. Therefore, even though substratum was largely determined by water mineral richness, it could not substitute the complex basicity gradient.

\section{Assemblage response}

Such a marked environmental change along the mineral richness gradient is likely to be of a considerable influence on the spring assemblages. Therefore, it is interesting that only a very limited number of studies noticed a significant effect of basicity on spring macroinvertebrate assemblages (Glazier \& Gooch 1987; Hahn 2000), though it has already been observed in several different organism groups (Horsák \& Hájek 2003; Pouličková et al. 2003; Hájek et al. 2006; Opravilová \& Hájek 2006). The most probable reason is that the effect of water chemistry in most studies was overridden by the variance in spring types (limno-, rheo-, and helocrenes included) or by insufficient length of the gradient of mineral richness.

On the other hand, an obvious assemblage response to mineral richness gradient was observed in amphipods (Glazier \& Gooch 1987; Hahn 2000), which can reach a very high abundance in springs, but avoid acidic environments, where they are absent. Hahn (2000) observed a considerably lower number of taxa at acidic rheocrenes compared to non-acidic (31 vs. 53 respectively). In part our results correspond to this trend. However, the number of chironomid taxa was lower also in the very basic conditions in our study. Despite the ranges of $\mathrm{pH}$ values being similar within the Hahn's $(4.1-7.9)$ and our (4.3 - 8.1) investigated springs, the results are not directly comparable, since Hahn compared the number of all taxa found in springs with $\mathrm{pH}$ higher than 5.6 to that of springs with $\mathrm{pH}$ lower than 5.6.

Despite the observed strong effect of the basicity gradient on the chironomid assemblages, the assemblage at habitat B was less systematic and predictable as judged by higher NMDS stress and lower portion of variance in the faunal data was explained by environmental variables. This might be a result of an expected higher temporal variability in temperature and oxygen concentration compared to habitat A, where the water was flowing (cf. Lindegaard 1995). The thin layer of almost standing water may be easily overheated if not shaded. This 
is difficult to measure and such data were not available for the analysis.

\section{Comments on some taxa}

Some of the collected taxa are known to be restricted to a narrow range of environmental conditions. For example Neostempellina thienemanni is known to inhabit calcareous springs with precipitation of limestone, which it uses for construction of transportable cases. Its preference for basic conditions is in agreement with its known ecological requirements. Stempellina bausei constructs transportable cases as well, but uses sand instead of limestone. It seems, therefore, that this species is not so restricted to extremely mineral-rich springs, but needs some inorganic material. As it is likely to prefer standing water habitats (more abundant at habitat B), moderately rich helocrenes probably represent its preferred choice.

The indicated preference for acidic conditions of one of the most abundant taxa, Paratendipes nudisquama is in agreement with records of this species from peaty habitats (peaty helocrene springs, moorland pools, etc.) (see Moller Pillot 2009). The ability of Chironomini to sustain acidic conditions has been explained by the buffering capacity of their hemoglobin (Jernelöv et al. 1981). Similarly, larger chironomids may be more tolerant of low $\mathrm{pH}$ because of their smaller surface to volume ratio (Wiederholm \& Eriksson 1977). This would explain the indicated preference of Macropelopia sp. (probably M. adaucta) to acidic conditions, which is in agreement with Vallenduuk \& Moller Pillot (2007).

Most of the taxa that showed an indication of preference for basic conditions were lotic (Tvetenia bavaricalcalvescens, Parametriocnemus stylatus, Synorthocladius semivirens and Heleniella ornaticolis). These taxa favoured basic conditions probably because of more abundant diatoms, a major lotic chironomid food item, compared to acidic conditions (Wrubleski 1987).

In conclusion, this study demonstrated that chironomid assemblages clearly changed along the gradient of mineral richness and provided the evidence of its effect on representatives of aquatic insects. However, due to the complex environmental change along the mineral richness gradient, it remains unclear about what is the causal mechanism: whether water chemistry, substratum, or both. Since the environment of helocrenes is naturally determined by water chemistry, laboratory experiments may well be necessary to shed more light on this question.

\section{ACKNOWLEDGMENTS}

We thank Markéta Omelková for her assistance in the field work. This study was supported by the Czech Science Foundation (P505/11/0779).

\section{REFERENCES}

Anderson MJ.2001. A new method for non-parametric multivariate analysis of variance. Austral Ecology 26. 32-46.

Blackwood MA, Hall SM, Ferrington Jr. LC. 1995. Emergence of Chironomidae from Springs in the Central High Plains Region of the United States. Journal of the Kansas Entomological Society 68(2) suppl.: 132-151.

Coffman WP. 1973. Energy flow in a woodland stream ecosystem: II. The taxonomic composition and phenology of the Chironomidae as determined by the collection of pupal exuviae. Archiv für Hydrobioilogie 71(3): 281-322.

Cox TF, Cox MAA. 2001. Multidimensional Scaling. Chapman \& Hall. $328 \mathrm{p}$.

Erman NA, Erman DC. 1995. Spring permanence, Trichoptera species richness, and the role of drought. Journal of the Kansas Entomological Society 68(2) suppl.: 50-64.

Ferrington Jr. LC. 1998. Generic composition of chironomid fauna in springs of North America. In: Botosaneanu L. Studies in Crenobiology. Backhuys Publishers, Leiden. pp 140-155.

Ferrington Jr. LC, Kavanaugh RG, Schmidt FJ, Kavanaugh JL. 1995. Habitat separation among Chironomidae (Diptera) in Big Springs. Journal of the Kansas Entomological Society 68(2) suppl.: 152-165.

Glazier DS, Gooch JL. 1987. Macroinvertebrate assemblages in Pennsylvania (U.S.A.) springs. Hydrobiologia 150: 33-43.

Hahn HJ. 2000. Studies on Classifying of Undisturbed Springs in Southwestern Germany by Macrobenthic Communities. Limnologica 30: 247-259.

Hájek M, Hekera P. 2004. Can seasonal variation in fen water chemistry influence the reliability of vegetation-environment analyses? Preslia 76(1): 1-14.

Hájek M, Hekera P, Hájková P. 2002. Spring fen vegetation and water chemistry in the Western Carpathian flysch zone. Folia Geobotanica 37: 205-224.

Hájek M, Horsák M, Hájková P, Dítě D. 2006. Habitat diversity of central European fens in relation to environmental gradients and an effort to standardise fen terminology in ecological studies. Perspectives in Plant Ecology, Evolution and Systematics 8: 97-114.

Horsák M, Hájek M. 2003. Composition and species richness of mollusc communities in relation to vegetation and water chemistry in the western Carpathian spring fens: The poor-rich gradient. Journal of Molluscan Studies 69: 349-357.

Ilmonen J, Paasivirta L. 2005. Benthic macrocrustacean and insect assemblages in relation to spring habitat characteristics: patterns in abundance and diversity. Hydrobiologia 533: $99-113$.

Ilmonen J, Paasivirta L, Virtanen R, Muotka T. 2009. Regional and local drivers of macroinvertebrate assemblages in boreal springs. Journal of Biogeography 36: 822-834.

Jernelöv A, Nagell B, Svenson A. 1981. Adaptation to an Acid Environment in Chironomus riparius (Diptera, Chironomidae) from Smoking Hills, NWT, Canada. Holarctic Ecology 4(2): 116-119.

Lencioni V, Marziali L, Rossaro B. 2011. Diversity and distribution of chironomids (Diptera, Chironomidae) in pristine Alpine and pre-Alpine springs (Northern Italy). Journal of Limnology 70(Suppl. 1): 106-121.

Lindegaard C. 1995. Chironomidae (Diptera) of European cold 
springs and factors influencing their distribution. Journal of the Kansas Entomological Society 68(2) suppl.: 108-131.

Lindegaard C, Brodersen KP, Wiberg-Larsen P, Skriver J. 1998. Multivariate analyses of macrofaunal communities in Danish springs and springbrooks. In: Botosaneanu L. Studies in Crenobiology. Backhuys Publishers, Leiden. pp 201-219.

Moller Pillot HKM. 2009. Chironomidae larvae. Biology and ecology of the Chironomini. KNNV Publishing, Zeist, $270 \mathrm{p}$.

Oksanen J, Blanchet FG, Kindt R, Legendre P, O'Hara RB, Simpson GL, Solymos P, Stevens MHH, Wagner H. 2011. vegan: Community Ecology Package. R package version 1.17-10. http://CRAN.R-project.org/package= vegan

Opravilová V, Hájek M. 2006. The variation of testacean assemblages (Rhizopoda) along the complete base-richness gradient in fens: A case study from the Western Carpathians Acta Protozoologica 45(2): 191-204.

Orendt C. 2000. The chironomid communities of woodland springs and spring brooks, severely endangered and impacted ecosystems in a lowland region of eastern Germany (Diptera: Chironomidae). Journal of Insect Conservation 4: 79-91.

Pouličková A, Bogdanova K, Hekera P, Hajkova P. 2003. Epiphytic diatoms of the spring fens in the flysh area of the Western Carpathians. Biologia 58: 749-757.

R Development Core Team. 2011. R: A language and environment for statistical computing. R Foundation for Statistical Computing, Vienna, Austria. ISBN 3-900051-07-0, URL http://www.Rproject.org/.

Smith H, Wood PJ. 2002. Flow permanence and macroinvertebrate community variability in limestone spring systems. Hydrobiologia 487: 45 - 58.

Thienemann A. 1924. Hydrobiologishe Untersuchungen an Quellen. Archiv für Hydrobiologie 14: 151-190.

Vallenduuk HJ, Moller Pillot HKM. 2007. Chironomidae larvae. General Ecology and Tanypodinae. KNNV Publishing, Zeist, $144 \mathrm{p}$.

Von Fumetti S, Nagel P. 2011. A first approach to a faunistic crenon typology based on functional feeding groups. Journal of Limnology 70(Suppl. 1): 147-154.

Von Fumetti S, Nagel P, Scheifhacken N, Baltes B. 2006. Factors governing macrozoobenthic assemblages in perennial springs in north-western Switzerland. Hydrobiologia 568: 467 - 475.

Wiederholm T, Eriksson L. 1977. Benthos of an Acid Lake. Oikos: 29(2): 261-267.

Wood SN. 2006. Generalized Additive Models: An Introduction with R. Chapman \& Hall/CRC, 391 p.

Wood PJ, Gunn J, Smith H, Abas-Kutty A. 2005. Flow permanence and macroinvertebrate community diversity within groundwater dominated headwater streams and springs. Hydrobiologia 545: $55-64$.

Wrubleski D. 1987. Chironomidae (Diptera) of peatlands and marshes in Canada. Memoirs of the Entomological Society of Canada 140: 141-161. 